\title{
POSITRON ANNIHILATION IN Pd-Ag-H AND Pd-Au-H SYSTEMS
}

\author{
E. DęBowska \\ Institute of Experimental Physics, Wroclaw University \\ pl. Maxa Borna 9, 50-204 Wrocław, Poland
}

Positron annihilation method was used to study hydrogenated $\mathrm{Pd}_{1-y} \mathrm{Ag}_{y}$ and $\mathrm{Pd}_{1-y} \mathrm{Ag}_{y}$ alloys in $\alpha$-phase. In both systems, insensitivity of the low-lying core states to the presence of hydrogen in the alloy was found. Rigid band model appeared to be a useless description of the changes in the band occupation after hydrogen absorption. The results seem to indicate that the "capacity" of the low-lying H-Pd bonding states remains constant when the $\mathrm{Ag}$ or $\mathrm{Au}$ atoms are added to $\mathrm{PdH} \approx 0.6$, which can explain the existence of the limit to the summed up hydrogen and $\mathrm{Ag}(\mathrm{Au})$ concentration.

PACS numbers: 78.70.Bj, 71.25.Pi, 71.90.+q

\section{Introduction}

In Ref. [1] the results of the positron annihilation studies, one-dimensional angular correlation of annihilation radiation (ACAR) and positron lifetime (PL), of hydrogenated $\mathrm{Pd}-\mathrm{Ag}$ alloys, $\mathrm{Pd}_{1-y} \mathrm{Ag}_{y} \mathrm{H}_{x}$ were presented. ACAR was shown to be a useful method to examine the electronic structure of $\alpha$-phase of this system. The investigation of $\beta$-phase systems, $\mathrm{PdH}_{x}$ as well as $\mathrm{Pd}_{1-y} \mathrm{Ag}_{y} \mathrm{H}_{x}$, failed because of a high concentration of lattice defects in the samples. The reader is asked to refer to Ref. [1] for the more detailed information about the $\mathrm{Pd}-\mathrm{Ag}-\mathrm{H}$ system, the sample preparation and the measurements.

In Ref. [2] a new fit, parabola + Ferrell function + wide gaussian $(P+F+$ $G_{\mathrm{w}}$ ), to long-range ACAR data for noble and $d$-transition metals was presented. The three functions were considered to represent the annihilation with three different electron groups: nearly free (NF), $d$-like and rare-gas core (rgc) electrons, respectively. This approach appeared to be a very good one when applied to the ACAR data for $\mathrm{Pd}-\mathrm{Ag}$ and $\mathrm{Pd}-\mathrm{Au}$ alloys [3]. In the paper we watched the changes, with $\mathrm{Ag}$ or $\mathrm{Au}$ concentration, of the numbers of nearly free and $d$-localized electrons per alloy atom. The linear characters of electron number changes throughout the concentration range testified convincingly against the possibility of RBM (rigid band model) application to explain the electronic structure of $\mathrm{Pd}-\mathrm{Ag}$ and $\mathrm{Pd}-\mathrm{Au}$ alloys. In this paper we would like to present the results obtained on the basis of the new, long-range ACAR data for the $\mathrm{Pd}-\mathrm{Ag}-\mathrm{H}$ system and compared them with 
the ones published in [1]. Main attention will be paid however to the hydrogenated $\mathrm{Pd}-\mathrm{Au}$ alloys.

$\mathrm{Pd}$-rich $\mathrm{Pd}_{1-y} \mathrm{Au}_{y}$ alloys absorb large quantities of hydrogen even at low pressure. At room temperature two phases may be observed in the $\mathrm{Pd}_{1-y} \mathrm{Au}_{y} \mathrm{H}_{x}$ system up to about $y=0.18$ [4]. One phase $(\alpha)$ is a solid solution of hydrogen in the metal, the second one $(\beta)$ represents a non-stoichiometric hydride phase with hydrogen atoms randomly occupying octahedral interstices leading to a defected $\mathrm{NaCl}$-type structure with the lattice parameter a few per cent higher than that in the corresponding $\mathrm{H}$-free alloy. At higher gold concentrations a continuous increase in the lattice parameter was observed over the whole hydrogen content range, thus indicating the existence of a single phase only. The experimental and theoretical works devoted to the examination of the electronic structure of $\mathrm{Pd}_{1-y} \mathrm{Au}_{y} \mathrm{H}_{x}$ system are very scarce, so further investigations to explain the hydrogen state in the system are desired.

\section{Measurements}

The samples of $\mathrm{Pd}_{1-y} \mathrm{Ag}_{y} \mathrm{H}_{x}$ were the same as in Ref. [1] except for the $\mathrm{Pd}_{0.55} \mathrm{Ag}_{0.45} \mathrm{H}_{0.16}$ sample, which had suffered destruction and was replaced by the new one $\mathrm{Pd}_{0.56} \mathrm{Ag}_{0.44} \mathrm{H}_{0.12}$. Hydrogenated $\mathrm{Pd}_{1-y} \mathrm{Au}_{y} \mathrm{H}_{x}$ samples were prepared by the direct reaction of the alloy samples with hydrogen during the repeated process of cooling from about $870 \mathrm{~K}$ down to room temperature. The system included five samples: $\mathrm{Pd}_{0.90} \mathrm{Au}_{0.10} \mathrm{H}_{0.49}, \mathrm{Pd}_{0.81} \mathrm{Au}_{0.19} \mathrm{H}_{0.34}, \mathrm{Pd}_{0.71} \mathrm{Au}_{0.29} \mathrm{H}_{0.19}$, $\mathrm{Pd}_{0.60} \mathrm{Au}_{0.40} \mathrm{H}_{0.12}$ and $\mathrm{Pd}_{0.50} \mathrm{Au}_{0.50} \mathrm{H}_{0.03}$ with about 0.02 uncertainty in the hydrogen concentration. The sample with $x=0.34$ was in substoichiometric $\beta$-phase and the remaining samples were in $\alpha$-phase as confirmed by X-ray data analysis.

For all the samples we have performed ACAR measurements in a wide range of angles (from -37 to 37 mrads) using a standard spectrometer with $1 \mathrm{mrad}$ resolution. As a source of positrons ${ }^{22} \mathrm{Na}$ isotope was used and the number of counts at maximum was equal to $(5-6) \times 10^{4}$. To measure PL spectra we used the spectrometer with $330 \mathrm{ps}$ time resolution and each spectrum embraced about $3 \times 10^{6}$ events. As for $\beta$-phase $\mathrm{Pd}-\mathrm{Ag}-\mathrm{H}$ samples [1] we observed the wavy, dull and uneven surface of the $\beta$-phase $\mathrm{Pd}_{0.90} \mathrm{Au}_{0.10} \mathrm{H}_{0.49}$ sample resulting from a high concentration lattice defects introduced by hydrogen. This observation has found its reflection in the long positron lifetime being equal to $\tau=(163 \pm 3) \mathrm{ps}$, the value as large as for the analogous sample of $\mathrm{Pd}-\mathrm{Ag}-\mathrm{H}$ system [1]. The results of the angular correlation measurements have also indicated the positron trapping in lattice defects. Thus the results that will be presented hereafter deal with the $\alpha$-phase $\mathrm{Pd}_{1-y} \mathrm{Au}_{y} \mathrm{H}_{x}$ system only.

\section{Results}

We have found practically no difference between the positron lifetimes for the samples before and after hydrogenation but it would be a speculation to conclude that it testifies to no change in the electron distribution; different kinds of electrons contribute to $\tau$ value. The correlation curves for the samples with and 
without hydrogen, normalized to the same area, differ only slightly with smaller hydrogen concentration leading to smaller difference. The analysis of the ACAR data for hydrogenated samples has shown that among different compositions of the parabolas, gaussians and Ferrell functions the $P+F+G_{\mathrm{w}}$ fit is the best one. Thus the model is the same as for $\mathrm{Pd}-\mathrm{Ag}(\mathrm{Au})$ alloys [3].

No change, in the error limits, appears in $G_{\mathrm{w}}$ characteristics ( $G_{\mathrm{w}}$ fraction and FWHM of this function) after hydrogen absorption by a given sample. It suggests no change in the distribution of the rare-gas core electrons. Thus, in both systems, deeply lying core states are insensitive to the $H$ presence. Using the same relation as in Ref. [1] we calculated the numbers $N_{\mathrm{NF}}$ of nearly free electrons per alloy atom and the differences $N_{s d}-N_{\mathrm{NF}}$ between the total number of $s$ - and $d$-like electrons $N_{s d}$ and $N_{\mathrm{NF}}$. These differences give the amount of electrons with localized wave functions of $d$-character while some contribution of itinerant wave functions of $d$-character are always contained in the NF electrons. Next, the changes in the numbers of NF and $d$-localized electrons between the hydrogenated samples and the corresponding hydrogen free alloys were calculated. Here are the results for both systems.

\section{1. $P d-A g-H$ system}

$N_{\mathrm{NF}}$ and $N_{s d}-N_{\mathrm{NF}}$ confronted with their values for the alloys before hydrogen absorption [3] are plotted in Fig. 1. From the differences $\Delta N_{\mathrm{NF}}$ and $\Delta\left(N_{s d}-N_{\mathrm{NF}}\right)$ in the numbers of electrons between hydrogenated samples and

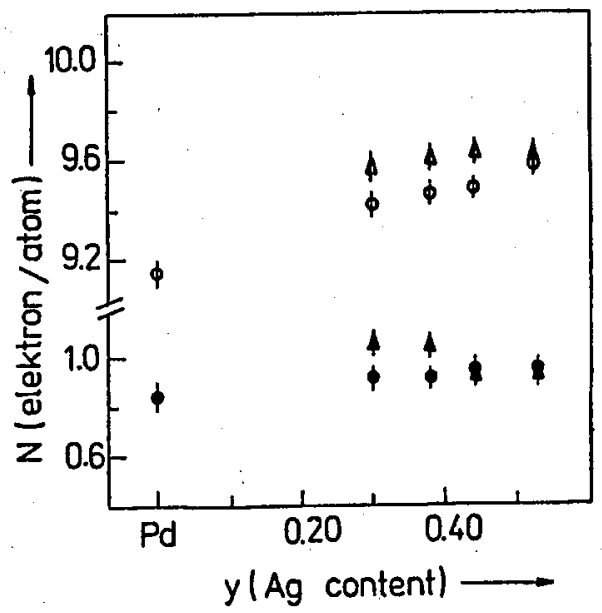

Fig. 1. Number $N_{\mathrm{NF}}$ (full symbols) of nearly free electrons as well as the differences $N_{s d}-N_{\mathrm{NF}}$ (open symbols) for $\mathrm{Pd}_{1-y} \mathrm{Ag}_{y} \mathrm{H}_{x}$ system (triangles) as compared to the same results for $\mathrm{Pd}_{1-y} \mathrm{Ag}_{y}$ alloys (circles). $x$ refers to the following samples: $\mathrm{Pd}_{0.70} \mathrm{Ag}_{0.30} \mathrm{H}_{0.31}$, $\mathrm{Pd}_{0.62} \mathrm{Ag}_{0.38} \mathrm{H}_{0.26}, \mathrm{Pd}_{0.56} \mathrm{Ag}_{0.44} \mathrm{H}_{0.12}, \mathrm{Pd}_{0.47} \mathrm{Ag}_{0.53} \mathrm{H}_{0.03}$. 
the corresponding hydrogen free $\mathrm{Pd}-\mathrm{Ag}$ alloys one can see that the rearrangement of the electrons after hydrogen absorption looks as such that for 30 and 38 at.\% $\mathrm{Ag}$ half of the $\mathrm{H}$ electrons are placed among the NF electrons and half go to the $d$-localized states. For Ag concentration being equal or higher than 44 at.\% Ag all the $\mathrm{H}$ electrons are delivered to $d$-band. Thus for the systems with smaller Ag concentration (higher $\mathrm{H}$ content) the new results fully confirm the conclusion from our previous paper [1], while the conclusion for the higher Ag concentration (smaller $H$ content) has changed somewhat; previously we obtained that $H$ electrons are delivered to $d$-band mostly but not fully.

It is worthwhile to notice that the numbers of $d$-localized electrons keep almost a constant value for all the samples, with $N_{s d}-N_{\mathrm{NF}} \approx 9.60 \pm 0.04$ (Fig. 1). This value is equal to $N_{s d}-N_{\mathrm{NF}}$ obtained for the alloys themselves (before hydrogenation) corresponding to $y \approx(55-60)$ at.\% Ag. A very interesting observation results from the extrapolation of this constant $N_{s d}-N_{\mathrm{NF}}$ value to the system with no $\mathrm{Ag}$ concentration, i.e. to $\mathrm{PdH}_{\approx 0.6}$ composition. Then the difference between $N_{s d}-N_{\mathrm{NF}}$ for $\mathrm{PdH}_{\approx 0.6}$ and pure $\mathrm{Pd}$ would be equal to $\approx 0.4$ electron/atom, the number of electrons that can be accommodated by the low-lying H-Pd bonding states in $\mathrm{PdH}[7,8]$. When $\mathrm{Ag}$ is added to $\mathrm{PdH}_{\approx 0.6}$ the "capacity" of this band remains constant and our observations are in compliance with the conclusion [9] that $\mathrm{Ag}$ pushes the $\mathrm{H}$ electrons out of the bonding band and transfers them to the $d$-states close to the Fermi energy. This leads to an increase in the total energy of the system and can explain the fact that $x \approx 0.60$ or $x+y \approx 0.60$ are the upper limits that one cannot pass beyond when hydrogenating pure $\mathrm{Pd}$ or $\mathrm{P}_{1_{-y}} \mathrm{Ag}_{y}$ alloys, respectively, under low hydrogen pressure.

\section{2. $P d-A u-H$ system}

The numbers of NF electrons for the samples with hydrogen are higher than for the alloy samples. This is presented in Fig. 2. We are not able to get an insight into each component of the system but the final result that can be seen outside is such that the $\mathrm{H}$ electrons are distributed in a different way for different $\mathrm{H}$ concentrations. This is seen from the differences in the numbers $N_{\mathrm{NF}}$ as well as $N_{s d}-N_{\mathrm{NF}}$ between the samples with and without hydrogen. When the concentration of hydrogen is large $(x=0.34)$ only about one-third of the electrons goes to the NF electron group and about two-thirds join a company of the localized $d$-electrons. For the systems with lower $\mathrm{H}$ content $(x=0.19,0.12$ and 0.05$)$ the electrons are distributed in equal measure among $\mathrm{NF}$ and $d$-electron groups.

The numbers $N_{s d}-N_{\mathrm{NF}}$ of $d$-localized electrons keep almost a constant value for all the samples, as it was observed in $\mathrm{Pd}-\mathrm{Ag}-\mathrm{H}$ systems, with $N_{s d}-N_{\mathrm{NF}} \approx$ $9.52 \pm 0.04$, the value a little bit smaller than previously. This number is equal to $N_{s d}-N_{\mathrm{NF}}$ obtained for the alloys themselves (before hydrogenation) corresponding to $y \approx(50-55)$ at.\% Au (Fig. 2). Since this concentration is just the upper limit of the summed up $y$ and $x$ values in $\mathrm{Pd}_{1-y} \mathrm{Au}_{y} \mathrm{H}_{x}$ samples that were produced by us, and $x \approx 0.60$ is the limit that one cannot pass beyond when hydrogenating pure Pd under low pressure of hydrogen, one may draw the conclusion that the situation is similar to that postulated for $\mathrm{Pd}-\mathrm{Ag}-\mathrm{H}$ system and regarding the 


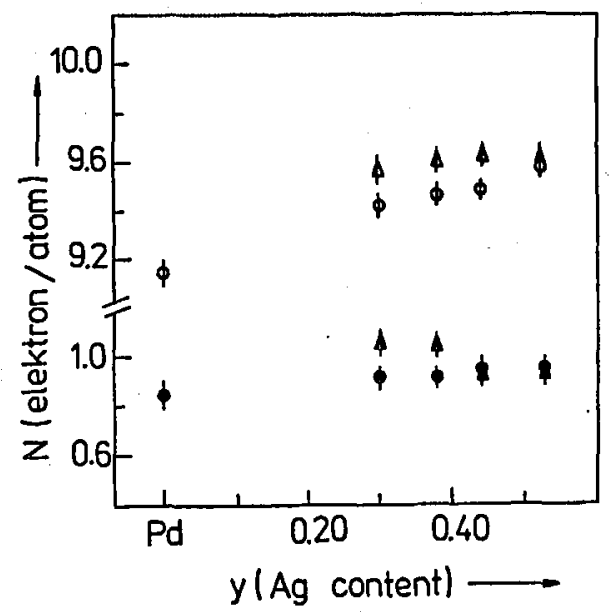

Fig. 2. Number $N_{\mathrm{NF}}$ (full symbols) of nearly free electrons as well as the differences $N_{s d}-N_{\mathrm{NF}}$ (open symbols) for $\mathrm{Pd}_{1-y} \mathrm{Au}_{y} \mathrm{H}_{x}$ system (triangles) as compared to the same results for $\mathrm{Pd}_{1-y} \mathrm{Au}_{y}$ alloys (circles). $x$ refers to the following samples: $\mathrm{Pd} 0.81 \mathrm{Au}_{0.19} \mathrm{H}_{0.34}$, $\mathrm{Pd}_{0.71} \mathrm{Au}_{0.29} y \mathrm{H}_{0.19}, \mathrm{Pd}_{0.60} \mathrm{Au}_{0.40} \mathrm{H}_{0.12}, \mathrm{Pd}_{0.50} \mathrm{Au}_{0.50} \mathrm{H}_{0.05}$.

relationship between the "capacity" of the Pd-H band and the upper limit of hydrogen - bsorption by pure $\mathrm{Pd}$ or $\mathrm{Pd}-\mathrm{Au}(\mathrm{Ag})$ alloys. It is interesting to notice that the numbers of $\mathrm{NF}$ electrons for all the hydrogenated $\mathrm{Pd}-\mathrm{Au}$ alloy samples are, in the error limits, the same and equal $\approx 1.0$. This indicates that the electron distribution in $\mathrm{Pd}-\mathrm{Au}-\mathrm{H}$ system is more uniform than in $\mathrm{Pd}-\mathrm{Ag}-\mathrm{H}$ one. We do not dare however to relate the fact to the existence, in the system with gold, of the non-bonding bands [5] rather than the low-lying bonding bands [6] that are characteristic for the system with silver [6,9].

The changes in the electron numbers in $\mathrm{Pd}-\mathrm{Ag}-\mathrm{H}$ and $\mathrm{Pd}-\mathrm{Au}-\mathrm{H}$ do not allow to state any essential difference in the electronic structure of the two systems. Unfortunately too high concentration of defects in $\beta$-phase $\mathrm{Pd}-\mathrm{Ag}-\mathrm{H}$ and $\mathrm{Pd}-\mathrm{Au}-\mathrm{H}$ samples makes the examination of this phase pointless. Such examination would certainly allow us to draw more conclusions about the electronic structure of these systems.

The work was supported by the Ministry of National Education within the research project 105/E-319/92.

\section{References}

[1] E. Dębowska, Z. Phys. B, Condens. Matter 79, 361 (1990).

[2] A. Baranowski, E. Dębowska, Appl. Phys. A 51, 23 (1990).

[3] E. Dębowska, Materials Science Forum 105-110, 635 (1992).

[4] A. Maeland, T.B. Flanagan, J. Phys. Chem. 69, 3575 (1965).

[5] W.M. Temmerman, Z. Szotek, private information. 
[6] D.A. Papaconstantopoulos, P.M. Laufer, A.C. Switendick, in: Hydrogen in Disordered and Amorphous Solids, Eds. G. Bombakidis, R.C. Bowman, Vol. 136, Nato ASI Series, Plenum, New York 1986, p. 139.

[7] A.C. Switendick, Z. Phys. Chem. Neue Folge 117, 89 (1979).

[8] M. Gupta, A.J. Freeman, Phys. Rev. B 17, 3029 (1978).

[9] W.M. Temmerman, A.J. Pindor, J. Phys. F, Met. Phys. 13, 1869 (1983); W.M. Temmerman, A.J. Pindor, B.L. Gyorffy, J. Phys. F, Met. Phys. 13, 1627 (1983). 